\title{
Approaches to the Team Establishment of Learning-typed Counselors in Agricultural Universities \\ --A Case Study of Jilin Agricultural University
}

\author{
Xiaohe $X u^{1, a}$, Di Sun ${ }^{1}$ \\ ${ }^{1}$ Jilin Agricultural University, Changchun, Jilin Province, China \\ axxhhezi@163.com
}

Keywords: learning organization; university counselors; team building.

\begin{abstract}
Based on Learning Organization Theory, this paper explores the approaches to the building of learning-typed counselors' teams in agricultural universities. It analyzes the necessity and a construction method of building such teams in agricultural universities. This method focused on three aspects: innovating the learning mechanism, enriching the learning contents, and building diverse learning platforms.
\end{abstract}

\section{Introduction}

The concept of "learning organization" derived from Jay Forrester, a professor from MIT (Massachusetts Institute of Technology) in the USA. In 1956, he put forward the original conception concerning "learning organization" in A New Corporate Design. Peter M. Senge, a student of Professor Forrester, is the founder of learning organization theory. His representative work is The Fifth Discipline----The Art \& Practice of the Learning Organization. Completed in 1990, it said that there are five factors that contribute to the building of a learning organization: building shared vision, team learning, improving mental models, personal mastery, and systematic thought.

A learning organization is an organization that continues to innovate and to make progress. It considers learning as its inherent feature. It requires its members to have the awareness of learning on their own initiatives, learning actively and trying their best to become good at learning. Then they can apply what they have learned into practice, and practice, in turn, can promote learning. Finally it forms a mutual promotion between learning and practice and both of them become better, creating a virtuous circle.

A learning-typed counselors' team means that when confronted with the challenges in the work of college students' ideological and political education in the new situation, all the members in this organization can establish the concept of lifelong learning and insist on the organic combination of learning and work. In addition, all the members have a common goal; that is, they can all realize that their central task is doing a good job of college students' ideological and political education, and their mission is to cultivate qualified builders and successors of socialism. What's more, the whole organization exhibits excellent teamwork skills, which means it can transform the learning ability of individuals into a team work force. It further emphasizes the cooperative learning among members of the organization. They share their learning achievements with one another and this multiplies the learning effects of the whole organization. Finally, all the members in this organization can constantly upgrade the contents and methods of college students' ideological and political education, continue to break the limits of their abilities and completely improve students' comprehensive quality.

\section{The Significance of Building a Learning-typed Counselors' Team}

The development of the times requires the building of a learning-typed counselors' team. Learning society requires the socialization and generalization of learning. It is a product of the era development and social progress, as well as the product of high-tech science and technology, information network and economic globalization. The essential feature is continuous learning, including lifelong learning, staff learning, and group learning, etc. 
At present, China is in the social transition. The formation of network society, the deepening of reform of higher education, and the change of student groups result in many new features of university students' ideological and political education. College counselors are a strong fighting force in ideological and political education, and play an important role in guiding the formation of academic atmosphere. Faced with the new situation, a learning-typed team of college counselors should be built to guide the whole society to cultivate learning-typed talents and undertake the responsibility of lifelong learning and staff learning, which would contribute to the formation of learning society.

College Counselors should continuously learn, establish the perception of collective learning, work together, make clear of new tasks, learn new skills and understand new ideas. Therefore, they would adapt to the development of our era.

The cultivation of professional, specialized and expert-oriented counselors requires the building of a learning-typed counselors' team. There is an increasing demand for the refinement of work concerning student affairs, but the roles of university counselors are not specifically divided and segregated. As a result, it increases the workload of them and has a bad effect on the progression and direction of the work concerning student affairs. Every year, there are university counselors who undergo job transfer, pursue further study and quit. A number of established counselors with mature working skills exit from the counselors' team, while newly-entered counselors still need a certain period of growth in terms of their working techniques and skills. This not only results in the instability of the whole counselors' team, but also hinders the specialized and professionalized development of this team. At present, many university counselors are young people who have participated in work only for a short time. They lack work experience. Because there is too much transactional work every day, they ignore the learning of political theories. Therefore, they can't achieve ideal pertinence and effectiveness when carrying out the ideological and political work. At the same time, the situation of college students' ideological and political education continues to change, which poses new challenges to counselors who engage in the work of college students' ideological and political education and administration. Therefore, it urges us to build a learning-typed counselors' team to make university counselors establish the concept of lifelong learning. In this team, university counselors can completely improve their abilities and qualities through learning. University counselors should also enhance collaborative learning and communication and share their learning achievements with one another, strengthening the cohesiveness and combat effectiveness of the counselors' team. Only when it does so can they closely follow the steps of the development of the times, keep pace with the times and constantly increase the effectiveness of college students' ideological and political education work.

We should build a learning-typed counselors' team, optimize and improve the overall qualities of counselors and achieve the professionalization, specialization and even expert-orientation of university counselors, so that this team can gain much by learning, harvest a lot through work, do things with platforms provided and have much space for further development.

The healthy growth of college students in the new times requires the building of a learning-typed counselors' team. Contemporary university students are born in the era of reform and opening-up and grow up in the time of social transformation. The students' family backgrounds, upbringing experience, thinking and behaviors are different from each other. Therefore, their educational objects, thinking pluralism, values, sources of gaining information and career choices are diverse. In this age of globalization, informationnization, networking and marketization, the university students' ideological and political education also face the conflicts and challenges of uniformity and diversity, modernization and westernization, globalization and nationalization. Facing these new situations and tasks, university counselors must learn consciously and diligently, continually deepen their understanding of university students' growth, and promote their overall healthy growth.

University counselors' outlook on life and concept of values as well as their moral characters and knowledge accomplishment have an important exemplary effect on college students. Building a learning-typed counselors' team can ensure that university counselors can closely follow the steps of 
the development of the times and keep pace with the times. It can also constantly improve university counselors' political quality, professional quality, organizational and administrative quality and psychological quality, so that they can imperceptibly influence students in the process of education. Specifically, university counselors should arm students with the Socialist Core Value System. They should educate and instruct students to scientifically understand the advanced theories of the Party and make students firmly hold confidence in the leadership of the Communist Party of China. What's more, university counselors should carry out timely education of current affairs and policies as well as analysis of hot issues. They should educate students to correctly view social issues and unhealthy phenomena, facilitate students to further understand the policies and guidelines of the Party and make students stick to the common ideal of the socialism with Chinese characteristics. Finally, university counselors should promote all kinds of advanced examples and models. They should strengthen the moral construction of students, direct students to increase their sense of responsibility and to establish the correct socialist concept of honor and disgrace, worldview and outlook on life and develop students to become talents with high comprehensive quality as well as the awareness of lifelong learning.

\section{Approaches to the building of learning-typed counselors' team}

In order to promote the building of a learning-typed counselors' team, to raise university counselors' ideological and political level and working abilities, to create a strong atmosphere of all-member learning, innovative learning and lifelong learning and to facilitate university counselors' executive power, creativity, cohesiveness and combat effectiveness, we should innovate the learning mechanism, enrich the learning contents and build learning platforms. Finally we can achieve the goals of improving university counselors' qualities, stimulating their energies, solving the problems they confront, promoting their work and advancing their development.

To innovate the learning mechanism. The building of learning-typed counselors' teams does not follow a single same model. Instead, we should take the actual situations of different universities into consideration and value the diverse learning needs of university counselors. In fact, sticking to the principle of diversity and achieving the diversification of working methods are the inherent requirements of learning organization building. In the building of a learning-typed counselors' team, the constant improvements of leadership mechanism, operation mechanism and incentive mechanism can effectively guarantee that university counselors' learning behavior can become more standardized and their learning effects become more significant.

We should improve the leadership mechanism and create a learning atmosphere fanning out from point to area. Specifically, we should establish a learning organization where the leader is the deputy secretary of the Party committee of the university who is in charge of the work concerning student affairs; the members of the leading group include the heads of related departments like Student Affairs Office, Communist Youth League Committee, Recruitment and Employment Office and College Students Psychological Counseling Center, as well as the deputy secretaries of the Party committees of different schools; this organization should also be equipped with a learning secretary. The responsibilities of the leading group include designing the learning schemes, creating new learning methods and inspecting and supervising the learning activities of all members.

We should improve the operation mechanism and bring about standardized and efficient learning behavior. Specifically, at the beginning of a year or a semester, we should formulate and improve the learning plans, learning schemes as well as the progression systems of periodic learning. We should also conduct timely improvement on the quarterly and monthly schemes of learning according to the major work arrangements made by the Party Central Committee, the provincial government and the municipal government. Furthermore, we should organically combine the decision-making, management, supervision and improvement of learning, making a Learning Improvement Journal for every learner (university counselor). As a result, individual learners can formulate daily, weekly, monthly, termly and yearly plans of learning and implement them. Then these learners can examine and improve their learning quality and learning efficiency. Learners (university counselors) should combine the innovative ideas put forward in the process of learning with their researches and projects 
on student affairs, write academic papers, carry out theoretical discussions, compile proceedings of colloquiums and sublimate the achievements of learning of theories.

We should improve the evaluation mechanism and create a learning atmosphere of rewarding the diligent and punishing the lazy. Specifically, the leading group should do timely random check on the learners' (university counselors') learning notes and examine their learning quality and effects. The leading group should also summarize and assess the completion and main achievements of the individuals in the organization and let them conduct self-evaluation. We should establish a scientific evaluation system as well as a system to supervise learning where cadres report their learning when reporting their work; the learning performance of a certain Party member is included in the appraisal of him/her; and the organization takes the learning performance of a certain member into consideration when examining him/her. Furthermore, we should combine the assessment of learning with the usual assessment, annual assessment, selection of the advanced and job promotion, so that we can achieve the normalization, institutionalization and standardization of evaluation and reveal the authority of this evaluation mechanism: it encourages the advanced, lashes the lagged and exhibits fair rewards and punishments.

To enrich the learning contents. Building a learning-typed counselors' team requires university counselors to firmly establish the concept that the speed of learning should be greater than that of change. University counselors should regard learning quickly, learning well and learning more as the pursuit of team learning. They should also regard being willing to learn and having techniques and competence of learning as the abilities that a standard counselor in the new times should have.

The work concerning student affairs is an integrated work that relies on theories and knowledge and needs to be put into practice and to keep pace with the times. It also has the property of timeliness. It is committed to the comprehensive development of students. It is a specialized profession and an enterprise. Therefore, we should improve the structure of knowledge according to the actual needs coming from the development of the team and different individuals (university counselors). We should appropriately determine the contents and key points of learning in different periods and formulate the medium and long term implementation plans for the learning of the organization. Not only should we focus on arming university counselors with theories, directing them to study Marxism-Leninism, Mao Zedong Thought, Deng Xiao-ping Theory, the important thought of "Three Represents", Scientific Outlook on Development and the latest achievements of the Party's theoretical innovation, to master the Marxist worldview and methodology and to become familiar with the principles of ideological and political work, but also should we instruct university counselors to master the knowledge of modern sciences and to become proficient with the knowledge of pedagogy, psychology, ethics, information science, sociology, law, and science of success. Furthermore, we should encourage university counselors to become experts not only in ideological and political work, but also in areas like mental health education, career planning, student affairs administration, student archives management, arts and humanities education, and education management.

To build diverse learning platforms. To begin with, we should build a learning and training platform for university counselors. We should insist on the combination of pre-work training, daily training, thematic training and training of backbone counselors. With the help of this platform, university counselors can take training-related programs according to their own interests and job demands. Through systematic training, we strive to make the structure of university counselors' knowledge and abilities become specialized out of broadness and expert out of specialization. What's more, we should build a quality development platform for university counselors. The quality development training focuses on increasing the communication between university counselors and enhancing their awareness of teamwork. It is an integrated training that is interesting and challenging, containing competition and entertainment in the process. It is also a useful attempt to the building of a learning-typed counselors' team. Finally, we should build a practice and communication platform for university counselors. We should provide support in terms of environment, time and conditions for university counselors on various aspects, including the setting up of their research projects, their attending of Party lectures and Youth League lectures, providing psychological counseling and vocational guidance for them and establishing elective courses, lectures and forums on areas like arts 
and humanities for them. We should also carry out university counselors' on-the-job training as well as seminars on student affairs, building a platform for university counselors to exchange and share their working experiences with one another and to achieve further understanding of their profession.

\section{Principles of building a learning-typed counselors' team}

To establish a new concept of learning. Establishing a new concept of learning requires university counselors to establish a brand-new concept of "making learning as work and making work as learning". They also need to figure out "why learning", "what to learn", "how to learn" and "effects of learning". Only when it does so can we produce the core learning ability for the sustainable development of a learning-typed counselors' team.

University counselors should regard learning as something pleasant. They should turn learning into their own internal needs, replacing no learning or interval, short-time learning in the past with initiative, active and continuous learning. Therefore, the transactional and experiential counselors' team of the past can be replaced by learning-typed counselors' team. University counselors should learn knowledge of theory of educational science, management and psychology on their own initiatives. They should also actively learn from experienced counselors and teachers and actively step into students and learn from them. Furthermore, university counselors should gain experience and learn lessons little by little in their everyday work, update the contents and methods of education in time, constantly investigate newly-emergent situations and solve new problems. Only when it does so can we guarantee that the counselors' team can accomplish the duty of educating people and university counselors can become good instructors and guiders for the growth of college students.

To combine individual learning and team learning. In a learning organization, individual learning is the basis of organization learning. Team learning is more important than individual learning, and it is the best way to perform the overall function of the organization and to enhance the wisdom of the whole team. Team learning is also an effective method for individuals to communicate abilities with one another and finally formulate new systematic abilities. The building of a learning-typed counselors' team not only requires university counselors to enhance individual learning, but also requires the counselors' team to strengthen team learning and team building.

Through individual learning, university counselors can become proficient with office software and master the theoretical knowledge of psychology, pedagogy, philosophy and sociology. University counselors should humbly ask experienced counselors for advice, so that they can make up for their weaknesses in work and master the techniques and doohickeys of their work. By taking advantage of modern technology (for example, building platforms and websites for ideological and political education, and opening personal micro-blog), university counselors can enhance their interaction and communication with students and master the working skills of the work concerning student affairs. The enhancement of individual learning and team learning can improve the professional qualities and working abilities of university counselors. It can further increase the efforts put into the work concerning student affairs and ideological and political education and ensure that the work of university counselors actually achieve the effects of ideologically educating students as well as managing and serving for them. Individual learning is the only way which must be passed in the growth of university counselors. It is also an important approach to the building of a learning-typed counselors' team.

Team learning can promote individual learning, improve individuals' learning abilities, facilitate individuals to grow quickly and direct the development of counselors' team building toward a good tendency. Team learning can also keep all the members of this team to work in a harmonious atmosphere, so that they can better learn from and communicate with one another, make up for their weaknesses and correct their errors, share their working experience and learning achievements with one another, perform the overall function of the organization, create brand new thinking style, break the limits of their own abilities and finally form a shared vision. Group is wiser with respect to individuals. Team learning can result in the full exchange of information between different counselors' teams (from different schools in a university), making them become an organic whole that exhibits better organizational performance and more vitality. 
To combine the building of a learning-typed counselors' team with the work of its progression. The purpose of building a learning organization is not for learning itself, but to enhance the organizational capacity. Thus, learning could be transformed the force of promoting work, which helps to cultivate innovative consciousness, spirit and ability, and improve the counselors' working philosophy and contents. Learning organization not only requires knowledge innovation and knowledge acquisition, but also requires the conversion of knowledge.

With the building of a learning-typed counselors' team, university counselors can strengthen their awareness of dedication, career-loving, diligence and professional enthusiasm on their own initiatives in the process of work. They can maintain strong senses of enterprise, responsibility and mission. They can also adhere to the student-oriented principle, care for students and serve for them. Specifically, university counselors should be diligent in learning, adjust their knowledge structure and take in new knowledge in time. They should enhance investigations and researches and focus on solving salient contradictions, figuring out difficult issues in the development and improving their work capacities. Finally, we can completely build learning-typed university counselors' team that is politically strong and professionally competent as well as having strict discipline and exhibiting upright daily behavior.

The building of a learning-typed counselors' team should put high value on actual effects, avoid formalism, prevent and overcome the tendency of "generalization" and "no practicality". We should soundly and carefully build such a team to reach the actual effects, which reflects the university counselors' satisfy and team establishment, and would finally benefit the students.

\section{References}

[1] Peter M. Senge. The Fifth Discipline [M]. GUO Jin-long (translator), Shanghai Joint Publishing Company, 1996.

[2] CHEN Qing-hua. The Strategies to Build the Team of Learning-typed University Counselors [J]. Ideological and Political Education Research, 2007 (4).

[3] LIN Cheng-hua. Learning Organization Theory and the Establishment of Grassroots Construction of Students' Party Branches in Colleges and Universities [J]. Ideological \& Theoretical Education, 2006 (11).

[4] LIU Yong-qin. Research on the Team Building of Learning-typed University Counselors [J]. Journal of Chizhou College, 2008 (5).

[5] LI Hui-fang, The Establishment of Scientific Learning Perceptions and Learning-typed Party Branches [N]. Ningbo Daily, 2010-09-24.

[6] WU Zhi-ming. The Significance and Focus of the Establishment of Learning Organizations [N]. Sanming Daily, 2010-12-12.

[7] ZHANG Zhen-gang. To Prove the Establishment of Learning Organizations with Organized Learning [N]. Guangzhou Daily, 2009-11-24. 